\title{
Carmelo Di Bartolo, the Design of a New Architecture of Materials Based on Bionics
}

\author{
Jimena Alarcón Castro \\ Universidad del Bío-Bío \\ jimenaal@ubiobio.cl \\ ORCID 0000-0002-4324-4369
}

\begin{abstract}
The approach referring to a new material architecture based on bionics, addresses a systemic component in favor of its efficiency, usability, ergonomics, experiences and function. In this sense, the Italian designer Carmelo Di Bartolo proposes as part of his philosophy, the consideration of design of materials integrating bionics, through a discourse and practice that values nature in the design process. Consider the product integrating a material-based approach as a suggestive and communicative element, or as a constitutive part of an efficient structure. The teachings of $\mathrm{Di}$ Bartolo are reflected in experiences developed in undergraduate and graduate education, as well as research in Chile. A reference being exemplified in the WINNER project that proposes the design of a dynamic facade based on the analysis of functional principles of nature, responsive to the solar energy capture.
\end{abstract}

Keywords

Emerging materials Material design Sustainability 


\section{Think With Limits, Ideate From the Origin}

Carmelo Di Bartolo has made undisputed contributions to design philosophy in Italy, however, what has not been disclosed is his contribution to design in Chile. Di Bartolo has practiced, linked and in parallel, both research and product design, in academic and business environments, with evident contributions sustained in a reflective, restless and honest look at design. With the Design Innovation laboratory foundation, he develops research and products for Fiat Auto, Fiat Research Center, Du Pont, de Nemours, Pirelli, Sony, Hyundai Motors, Motorola Advanced Concept, Lego Futura and Gillette among many others, while creating the Centro Ricerche in Milan and the Masters in Bionics at the European Institute of Design (IED). The link with Chilean design was produced with his first visit to Chile in the last decade of the past century and continues to the present day, with a legacy based on two aspects that nourish national design, placing bionics first as a capable methodology to systematically drive the design process, and secondly, bringing to the forefront the design of materials as a new theme to be addressed from design. For Di Bartolo, bionics emerged as a value in his project perspective, together with the basic design practiced with his students at the beginning of their professional life and motivated by his professors Roberto Lucci and Paolo Orlandini, who had studied at the Illinois Institute of Technology in Chicago at the Mies van de Rohe School, and they carried out this typology of exercise to empirically understand structure and formal phenomena. Di Bartolo mentions in an interview conducted in Milan in 2016: "First year design students want to be artists, but you have to know the limits as a basis for creativity and establish developments to overcome them with the minimum use of energy. There is an enormous amount of experiences in architecture, such as the work of Pier Luigi Nervi, Felix Candela and Buckminister Fuller, who have worked to build a house, a building, with the least use of materials, Gaudí himself worked with the catenary, where the curve is used to identify the shortest route from one point to another. So, when you create an experience, through a challenge with the students, you can create jobs and hyperstatic structures, that is to say, in balance" (Alarcón, 2016). According to Di Bartolo, in design, thinking with a limit stimulates creativity, if there is no limit, everything is self-referential. The designers have to respond to links to usability, ergonomics, materials, market, experiences, in short, they have to listen. On the other hand, the artist does not have to justify anything to anyone. So, basic design fosters an attitude of curiosity, of necessary search, since a designer who discovers, who deconstructs, is capable of creating, because they have learned design based on experiences, on playing, because the play allows one to discover a world that existed before. Bionics was born from that step between basic design and experimentation. "The bionic designer constantly applies a type of reverse engineering towards nature. They seek to unveil functional mechanisms that may be useful for their objects. Once these mechanisms have been individualized, the porting operation from the natural to the artificial domain is a kind of reinterpretation of nature that establishes the relationship of similarity" (Di Bartolo \& Montanari, 2004). 


\section{Approach to Material Design}

Materials innovation for industry has been a theme for designers since the discovery of catalyzed olefin polymerization by Ziegler and Natta, Nobel laureates in 1963. Until then, materials innovation had been indisputably in the territory of chemistry and engineering. However, starting in the 1960s, in Europe, but even more so in the United States of America, architects and designers value the idea that the material can be designed. The milestone of Ziegler and Natta proved that profound transformations were possible in the field of chemistry and polymer technology to achieve new configurations of matter. So why couldn't high standard interventions occur in aesthetics and communication skills (Alarcón et al., 2020). With the innovation of plastics, color, design, creative professionals consider the possibility of intervening in the appearance of materials, beyond simple surface treatments (Claverie \& Schaper, 2013). Over the years, multiple industrial materials developments have emerged. However, with the growing evidence of climate change, waste and pollution, environmental effects have shown that the consumption of materials of this nature is not a sustainable alternative (Ashby \& Johnson, 2013). Current approaches referred to the design of new materials are related to the existence of a greater global awareness about energy dependence and the unfavorable consequences for the economy and lifestyle (Ashby, 2016; Happaerts, 2014). Sustainability and the efficient use of resources is an important driver for applied research in materials. The definition of materials in today's design is more extensive than ever. Designers add computational programmability to conventional materials such as wood and plastics, to develop compositions that are more expressive in form and function (Correa et al., 2015; Ishii et al., 2012). They collaborate with microorganisms, guiding their growth and forging the conditions in which materials can be created, inspired by the propagation of the root of a plant to find light and nutrition (Cogdell, 2011). A concrete example is the BioLogic Project of the Massachusetts Institute of Technology (MIT), Tangible Media Group (Yao et al., 2015), explores receptive clothing, whose dozens of small triangular fins react to heat and humidity, due to the trillion single celled organisms embedded in the fabric. Digital technologies such as 3D printing allow for the automatic execution of patterns necessary to achieve particular bending angles, enabling new material configurations (Scheunemann et al., 2015). The redefinition of the design of new material proposals implies a deep understanding of the scenario and practices to be developed. It is necessary to meet sustainability standards, due to increased environmental regulations and consumer awareness. A correct and coherent administration of resources, as well as the devising of strategies appropriate for these requirements is as necessary as it is essential (Beylerian et al., 2008; Blanpain et al., 2016; Briede \& Alarcón, 2012). In an emerging design landscape, research and experimentation that deepens the understanding of these new practices is fundamental (Camere \& Karana, 2018). While the ubiquity of new materials and developments is a growing phenomenon, technologies offer a wide spectrum of potential for creating design and product concepts. Design today needs to seek appropriate 
approaches, strategies, and tools to work with new materials generating change, growth, and responses to the environment. Design must spend time addressing different aspects of materials, generating an experiential understanding, fostering a new generation of materials and ways of thinking related to their nature and conception (Bing-Chung et al., 2001).

\section{Bionics and a New Material Architecture}

In a context related to a new material culture, an approach referring to its new architecture arises. Research has carried out different methodologies to develop proposals based on the principles of bionics, which is based on the study of natural systems that, although morphologically different from each other, function in a similar way. It is defined as the abstraction of good design from nature or an emerging discipline that emulates the designs and processes of nature to create a healthier and more sustainable planet (Arruda, 2020). Unlike the simple translation of biomorphic elements from biology to product design, knowledge transfer occurs at the performative level, through the analysis of strategies based on the way nature solves problems. It involves deep morphological analysis to reveal the mechanisms, formal, geometric, and functional organization relationships, to obtain an imaginative approach and the choice of a scalable phenomenon. In this natural cyclical economy, each residue from one process becomes the raw material for another, which is why cycles close (Peters, 2011; Dicks, 2016). Research for the design of a new material architecture with a focus on bionics is capable of generating responsible solutions to technical, emotional, and application attributes. It allows for the integration of appearance and structure in unison and balance, for the definition of requirements in the three mentioned dimensions. This type of materials could be self-repairing, adapt to environmental conditions, for example, to different seasons of the year, it could be made up of highly sustainable materials and could be composed with minimal effort and energy savings. Bionics is a relevant input to reveal a new materials architecture, as it provides the possibility of connection between principles existing in nature, to satisfy technical, emotional, and application requirements, through the creation of meaningful knowledge, delivering responses with innate characteristics, behavior, and performance capacity, proposing new solutions and redefining future attributes that address the project of new material from the structure to its appearance.

\section{Carmelo Di Bartolo and the Integration of a New Materials Architecture in Chile}

The systematic and methodological incorporation of bionics in academic context in Chile, as well as developments carried out especially for the panel industry, have strengthened the traditional design process (Prodintec, 2006). Industrial design in Chile has been aimed at putting consumer goods on the market that are classified within the final product category, while the development of mate- 
rials has been relegated to the field of engineering. The approach to Italian design, through Carmelo Di Bartolo to academic environments in the country and the teachings collected by Chilean disciples in Design Innovation at the beginning of this century result in the incorporation of a new approach to product design, which is evidenced in the research developed for the company Masisa S.A. called Biomas (Contreras, 2000) and Bionics and Innovative Design (Alarcón, 2003). It is in the Biobío Region where research related to the design of wooden materials has been developed, integrating texture design based on affective engineering for the competitive differentiation of the industrial sector of wooden panels Fig. 1. As well as various international cooperation projects addressing the design of materials based on waste Fig. 2. Material design was born in Chile focused on the design of new alternatives for the wood panel production section, seeking to advance both at the level of substrates, formats, and appearance perceived by users. Materials design workshops are developed in design schools and students begin to understand that the design of the material can precede the design of the object or that the design of a material can constitute in itself a project of ideation of a product, which opens up an important research and development focus for design as a discipline. A contemporary look at the project in its conceptual phase, assesses the potential of the sensory experience possible to perceive by users, through the expression of the materials. Traditionally, the material has been conceived as an elemental operator, whose main task was to give structure to a more complex system. However, in the new situation, the material can present an intrinsic complexity, managed by the designer to give presence to the object that makes it capable of performing functions (Manzini, 1986).
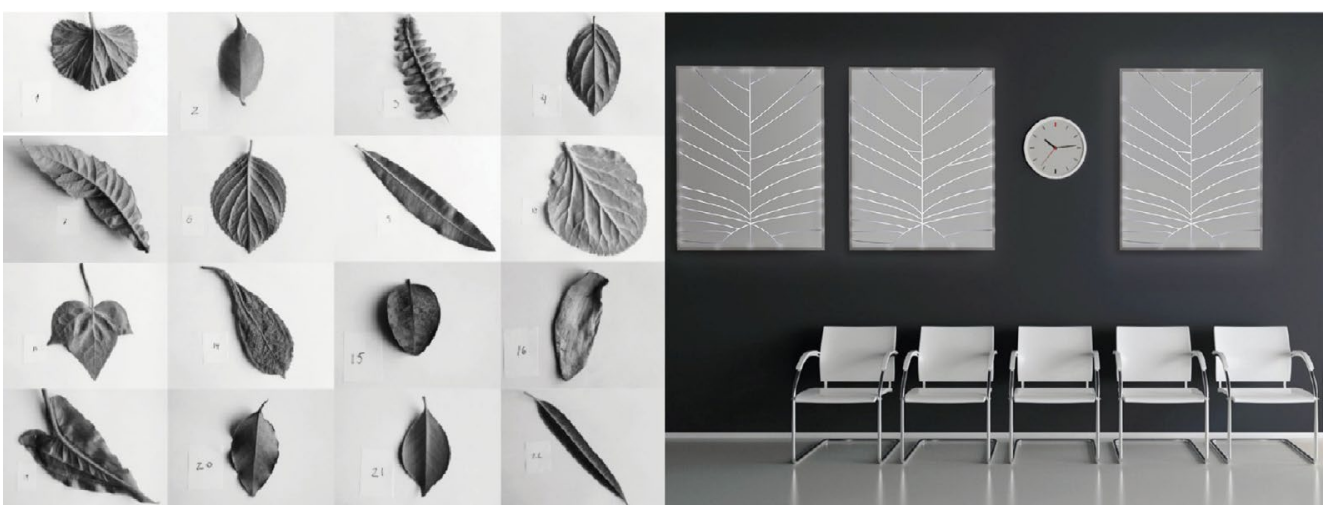

Fig. 1

Illuminated sensory panels. Master's dissertation project in Wood Construction, Universidad del Bío-Bío, Chile by Gino Ormeño. Source: Project file 


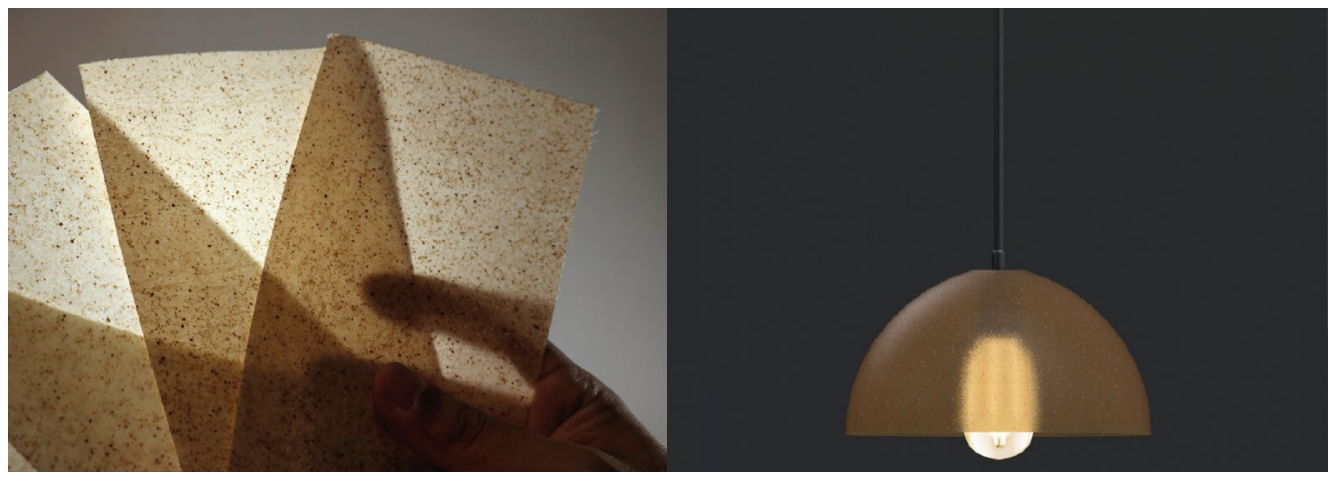

\section{Bionics Applied to the WINNER Project}

The WINNER project arises from the collaboration between European and Latin American entities, receiving funding from the European Commission, through the ERANET LAC program. This program arises as a measure to strengthen international collaboration between these regions, especially in the field of technological innovation. The project consortium is complementary in terms of the partners' expertise and their capabilities span different areas, such as energy efficiency, sustainable design, nanotechnology, and manufacturing technologies. This proposal aims to design a smart dynamic facade system to capture solar energy, integrating the photovoltaic crystals designed in the framework of the project and the electronic system, whose requirement is to provide maximum potential and efficiency in solar capture. The research allows for defining the conceptual design of a smart dynamic facade for photovoltaic crystals, which includes bionics concepts. It considers properties of the visual plot and the perception of this configuration, which, for some authors (Karana et al., 2016), results essentially from the structural ordering of the elements that compose it. Photovoltaic crystals react by capturing solar energy from the environment and function as a system integrated into the modular structure that contains them. The photovoltaic crystals support system assumes a modularity strategy, subdividing the glass surfaces into smaller sections to reduce the impact of the wind. The system is divided into glass modules with a smaller area in order to increase the available perimeter to install the photovoltaic cells contained in the glass perimeter. The origin and directionality of the sun are dynamic, varying according to the movements of translation during the year and rotation during the day, configuring a modular system in two levels of movement to capture solar energy. Carmelo Di Bartolo suggests integrating the bionic observation typical of positive phototropism, in which the plant modifies its position facing the sun to capture its rays with maximum efficiency (Mulkey et al., 1981), observing the sunflowers and their movement to capture sunlight; as well as the concept of phyllotaxis, referring to the arrangement of the leaves on the stem to integrate into the design of the dynamic facade system. The glass composed of nanoparticles are inserted into a structure forming an active module, which in turn, is part of a system designed from bionic observation Fig. 3-4.
Fig. 2

Materials developed with plastic waste at the Center for Nanotechnology and Smart Materials (CeNTI), Portugal, for the REDES project, Universidad del Bío-Bío, Chile. Source: Project file 


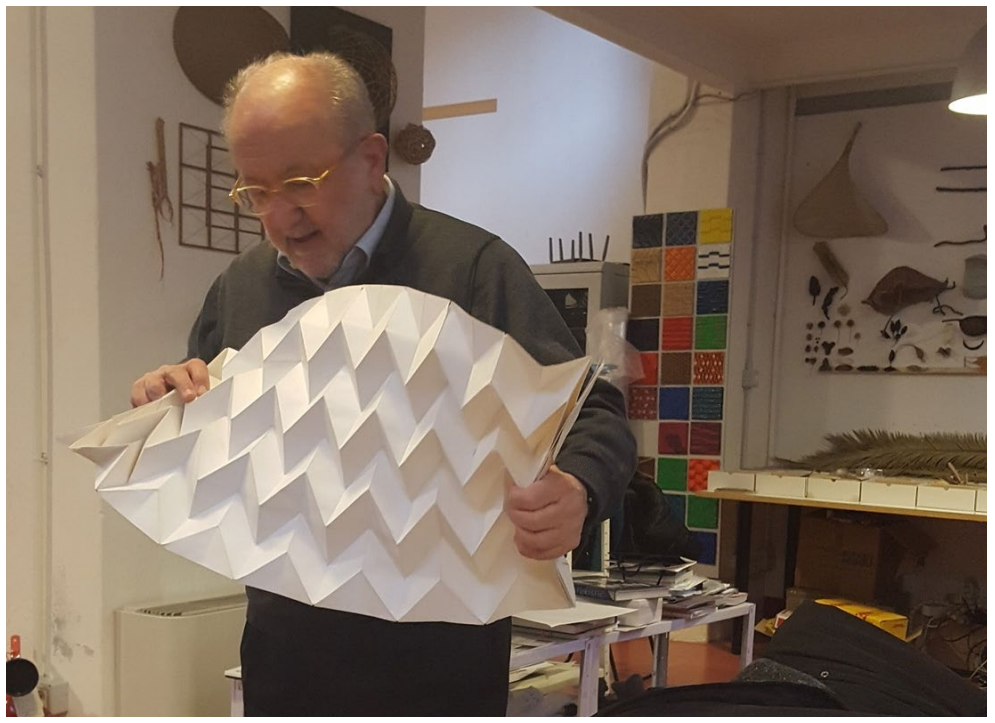

Fig. 3

Study of leaves by Carmelo Di Bartolo, Design Innovation, Italy. Source: Project file

System Evolution / Dynamic

Smart / Responsive

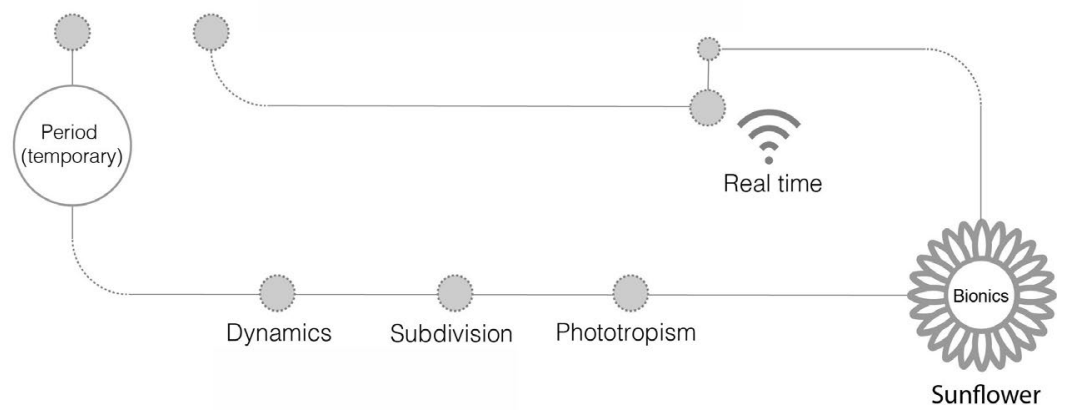

Di Bartolo's orientation regarding the bionic referents to observe was fundamental for the project's design team. Finally, the smart dynamic facade system contains photovoltaic crystals that have the ability to react to solar stimuli, capturing energy. The structural system that supports them is based on phototropy, the principle of biomimicry that, through dynamic movements, improves the angle of energy capture for better use and efficiency Fig. 5-6.

Fig. 4

Systemic development of a facade based on bionic studies of sunfl wers. Source: Project file 


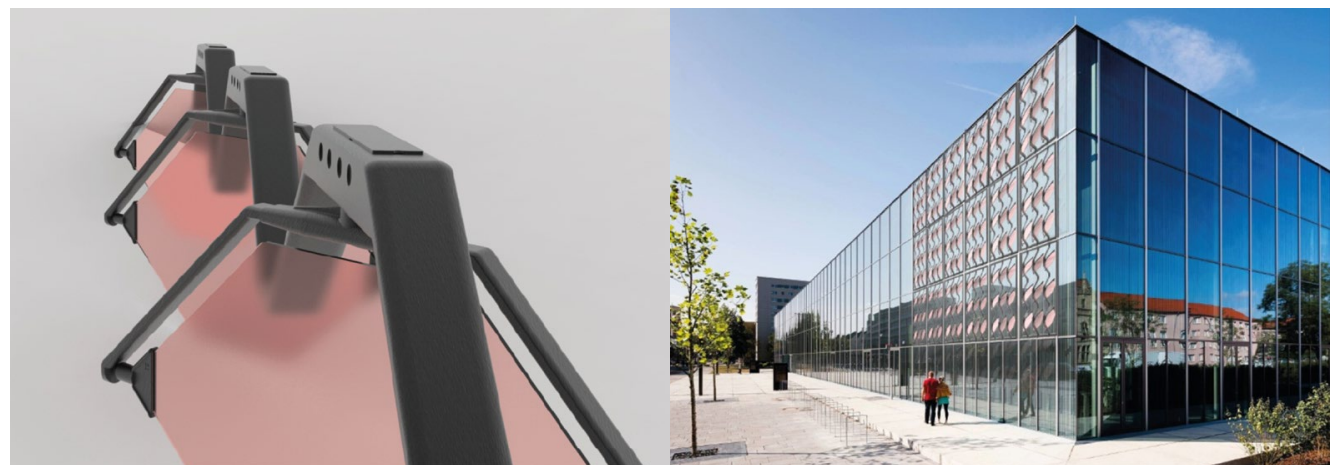

\section{Conclusion}

The methodological approach applied in the context of the experiences carried out in Chile, is based on the observation of nature as a reference to deliver project responses and its potential as a foundational engine of innovation in the field of materials design. Nature proves to be a source of inspiration for design, allowing for the generation of integral solutions that contribute to the design process and its results. A wise choice of natural references and a correct interpretation of their functionality are essential. In this context, the philosophical work of Carmelo Di Bartolo is inserted, in the new material culture that takes over the study of bionics, through the charactersitics that nature has endowed with living organisms, in order to reference the learned way to interpret and apply it in the practice used for the generation of innovation. The approach of Italian design to academic environments in Concepción, Chile, through the philosophy of Di Bartolo, allows for integrating a new approach to design. Particularly at the Universidad de Bío-Bío, research has been carried out on the design of materials and teaching experiences at the undergraduate and graduate level, since 2000. The cultural legacy of Di Bartolo has impacted on the training of more than fifteen generations of students of the Industrial Design career, who have integrated into their knowledge the relevance and interventions of bionics for the benefit of a project. In the field of research, material design is installed as a new development alternative for design in Chile, focused on the design of new solutions for the wood panel production sector. Currently, multiple developments of biobased materials have been focused on the use of waste to seek more sustainable answers for highly polluting materials. Students understand that the design of the material can precede the design of the object, constituting itself, in a project of ideation of a product.
Fig. 5

Dynamic facade modules developed within the framework of the WINNER project. Source: Project file

Fig. 6

Dynamic facade simulation modules of the WINNER project. Source: Project file 
They advance in the practice of concepts such as circular design applied to this area. The scope of bionics and, with it, the teaching of Di Bartolo, has been transversal and unprecedented in this context, providing a more complete, responsible and timeless perspective of design, which is called new material architecture.

\section{Acknowledgements}

ANID project N REDI170581.
Jimena Alarcón Castro Ph.D. in Design Management, Universidad Politécnica de Valencia. Master in Wood Construction, Universidad Bío-Bío. Industrial Designer, Universidad de Valparaíso. Professor at the Universidad del Bío-Bío, Head of Centre for Entrepreneurship and Innovation to Design, Chile. Vice President of the Ibero-American Network for Research in Design, Spain. 
Alarcón, J., Celaschi, F. \& Celi, M. (2020). Diseño de materiales: del Basic design al Material Driven Design. Cuadernos del Centro de Estudios de Diseño y Comunicación, 114, 59-71.

Alarcón, J. (2016). Entrevista a Carmelo Di Bartolo en Design Innovation, Milan, Italy.

Alarcón, J. (2003). Biónica y Diseño Innovativo: el sector manufacturas de madera y oportunidades para la generación de nuevos materiales. Master's dissertation in Wood Construction, Universidad del Bío-Bío, Chile, guided by Carmelo Di Bartolo.

Arruda, A. (Ed.). (2020). Bionica e Design. Experiencia memorable de 30 protagonistas. Blucher. https://www. blucher.com.br/livro/detalhes/bionica-e-design-1595/ arquitetura-e-design-117

Ashby, M. (2016). Materials and Sustainable Development (1st Ed). Butterworth-Heinemann.

Ashby, M.F., \& Johnson, K. (2013). Materials and design: the art and science of material selection in product design. Butterworth-Heinemann.

Bing-Chung, C., Silva, E., \& Kikuchi, N. (2001). Advances in computational design and optimization with application to MEMS. International Journal for Numerical Methods in Engineering, 52(1-2), 23-62.
Beylerian, G.M., Dent, A., \& Quinn, B. (2008). Ultramateriales. Formas en que la Innovación en los Materiales Cambia el Mundo (1st ed). Blume.

Blanpain, B., Meskers, C., Olivetti, E., Apelian, D., Howarter, J., Kvithyld, A., Mishra, B., Neelameggham, N., \& Spangenberger, J. (2016). (Eds.). REWAS 2016: Towards Materials Resource Sustainability, Conference proceedings. Nashville.

Briede, J., \& Alarcón, J. (2012). Estrategias sustentables aplicadas al contexto regional: diseño de tableros de madera y materias primas no convencionales para revestimiento decorativo. Interciencia, 37(12), 927-933.

Camere, S., \& Karana, E. (2018). Fabricating materials from living organisms: An emerging design practice. Journal of Cleaner Production, 186, 570-584.

Claverie, J. P., \& Schaper, F. (2013). Ziegler-Natta catalysis: 50 years after the Nobel Prize. Mrs Bulletin, 38(3), 213-218.

Cogdell, C. (2011). From BioArt to BioDesign. American Art, 25(2), 25-29.

Contreras, F. (2000). Biomas. Master's dissertation in Bionics from the Milan Institute of European Design, guided by Carmelo Di Bartolo.
Correa, D., Papadopoulou, A., Guberan, C., Jhaveri, N., Reichert, S., Menges, A., \& Tibbits, S. (2015). 3D-printed wood: programming hygroscopic material transformations. 3D Printing and Additive Manufacturing, 2(3), 106-116.

Di Bartolo, C., \& Montanari, R. (2004). Pensar/Proyectar el Futuro. Cuadernos de Diseño, 1, 701-884. Istituto Europeo di Design Espana.

Dicks, H. (2016). The philosophy of biomimicry. Philosophy \& Technology, 29(3), 223-243.

Happaerts, S. (2014). International Discourses and Practices of Sustainable Materials Management. In Report $n^{\circ} 5$ (pp. 12-13). Policy Research Centre for Sustainable Materials Management.

Ishii, H., Lakatos, D., Bonanni, L., \& Labrune, J.B. (2012). Radical atoms: beyond tangible e bits, toward transformable materials. Interactions, 9(1), 38-51.

Karana, E., Pedgley, O., Rognoli, V., \& Korsunsky, A. (2016). Emerging Material Experiences. The Journal of Materials and Design, 90, 1248-1250. https:// doi.org/10.1016/j.matdes.2015.07.042

Manzini, E. (1986). La materia dell'invenzione. Materiali e progetto. Arcadia.
Mulkey, T., Kuzmanoff, K., \& Evans, M. (1981). Correlations between proton-efflux patterns and growth patterns during geotropism and phototropism in maize and sunflower. Planta, 152(3), 239-241. 10.1007/ bf00385150.

Peters, T. (2011). Nature as measure: The biomimicry guild. Architectural Design, 81(6), 44-47.

Prodintec, F. (2006). Diseño Industrial. Guía Metodológica Predica. "Cómo integrar el diseño en su empresa". Gráficas Rigel.

Scheunemann, L., Balzani, D., Brands, D., \& Schröder, J. (2015). Design of 3D statistically similar Representative Volume Elements based on Minkowski functionals. Mechanics of Materials, 90 , 185-201.

Yao, L., Ou, J., Cheng, C. Y., Steiner, H., Wang, W., Wang, G., \& Ishii, H. (2015). BioLogic: natto cells as nanoactuators for shape changing interfaces. In Proceedings of the 33rd Annual ACM Conference on Human Factors in Computing Systemss (pp. 1-10). 